\title{
Clinical outcomes of multilevel anterior corpectomy and fusion as a revision surgery of the cervical spine: report of seven cases
}

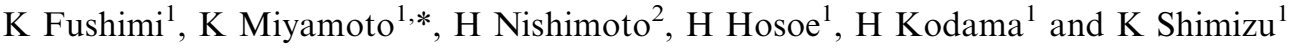 \\ ${ }^{1}$ Department of Orthopaedic Surgery, Gifu University School of Medicine, 1-1 Yanagido, Gifu, Japan; ${ }^{2}$ Department of \\ Orthopaedic Surgery, Gifu Central Hospital, 3-25 Kawabe, Gifu, Japan
}

\begin{abstract}
Study Design: Report of seven cases.
Objective: There is no general consensus on the best surgical procedures for late-onset complications of cervical operations. We reported seven patients who had been treated effectively by multilevel anterior corpectomy and fusion (ACF) as revision surgery of the cervical spine.

Setting: Gifu University Hospital, Gifu, Japan.

Method: Multilevel ACF using autogenous fibular strut graft as revision surgery was performed on seven patients: four patients having disorders of adjacent discs after anterior discectomy and fusion and three patients having postlaminoplasty disorders. Japanese Orthopedic Association scores (JOA scores) of the cervical myelopathy and severity of radicular and axial pains were used to evaluate outcomes.

Results: Rigid osseous fusion was achieved in all patients. JOA scores of the cervical myelopathy and the radicular pain, which had worsened just before the revision surgery, were improved significantly.

Conclusion: In the present seven patients who had variety of pathological conditions with various previous surgeries, multilevel ACF using strut graft was effective as a revision procedure in ameliorating their symptoms.
\end{abstract}

Spinal Cord (2006) 44, 449-456. doi:10.1038/sj.sc.3101868; published online 29 November 2005

Keywords: revision surgery; corpectomy; fusion; cervical spine

\section{Introduction}

Developments of various surgical procedures, such as anterior $^{1-3}$ and posterior decompression surgery ${ }^{4-6}$ for cervical spondylotic myelopathy and ossification of the posterior longitudinal ligament (OPLL) have provided patients with satisfactory outcomes. ${ }^{1-6}$ Several long-term follow-ups of these operations, however, have indicated late-onset complications, including degeneration of adjacent discs and pseudoarthrosis after cervical fusion, ${ }^{7-9}$ and recurrence of spinal canal stenosis after expansive laminoplasty. $6,10,11$

Complications in such cases often involve a combination of factors, such as instability, compression of the spinal cord and nerve roots by spurs, herniated discs, ossified masses, and malalignment of the cervical spine. ${ }^{6,10-12}$ As revision procedures for these complications, posterior approaches such as interspinous wiring, ${ }^{13,14}$ foraminotomy, ${ }^{15}$ and posterior fusion, ${ }^{16}$ or

*Correspondence: K Miyamoto, Department of Orthopaedic Surgery, Gifu University Graduate School of Medicine, 1-1 Yanagido, Gifu 501-1194, Japan anterior corpectomy and fusion $(\mathrm{ACF})^{9,17,18}$ have been performed in accordance with the pathological conditions. Here, we report efficacies and pitfalls of multilevel ACF using a fibular strut graft as revision cervical surgery. Although this study reviews only a small number of patients as a preliminary study, it is suggested that multilevel ACF using strut graft is one of the effective solutions for a variety of symptoms following failed cervical surgery.

\section{Materials and methods}

\section{Materials}

Seven patients, six men and one woman, with a mean age of 53.6 years, participated in this study (Table 1). They had all undergone surgical treatment for cervical myelopathy, but the outcomes were unsatisfactory. Four patients who had undergone anterior discectomy and fusion exhibited new disorders at adjacent discs (patients 1-4) (Figure 1a and b) and three patients who had undergone laminoplasty exhibited a 
Table 1 Summary of seven patients who underwent subtotal corpectomy as revision surgery

\begin{tabular}{|c|c|c|c|c|c|c|c|c|}
\hline \multirow[b]{2}{*}{ Patient no. } & \multirow[b]{2}{*}{ Age } & \multirow[b]{2}{*}{ Sex } & \multicolumn{2}{|c|}{ First operation } & \multicolumn{3}{|c|}{ Second operation (revision surgery) } & \multirow[b]{2}{*}{$\begin{array}{l}\text { Postop. follow- } \\
\text { up period } \\
\text { (years) }\end{array}$} \\
\hline & & & Initial diagnosis & Method of operation & $\begin{array}{l}\text { Diagnosis at the second operation, } \\
\text { or reason for failure }\end{array}$ & $\begin{array}{l}\text { Corpectomy } \\
\text { levels }\end{array}$ & $\begin{array}{c}\text { Duration } \\
\text { between first } \\
\text { and second op. } \\
\text { (years) }\end{array}$ & \\
\hline 1 & 58 & M & Disc herniation & ${ }^{\mathrm{a}} \mathrm{AF}(\mathrm{C} 5-6),{ }^{\mathrm{b}} \mathrm{PW}(\mathrm{C} 5-6)$ & $\begin{array}{l}\text { Disorder of adjacent discs }(\mathrm{C} 4-5, \mathrm{C} 6-7) \\
\text { radiculo/myelopathy }\end{array}$ & $\mathrm{C} 5,6$ & 2.2 & 5.8 \\
\hline 2 & 68 & M & Disc herniation & ${ }^{\mathrm{a}} \mathrm{AF}(\mathrm{C} 3-4, \mathrm{C} 5-6-7)$ & $\begin{array}{l}\text { Disorder of adjacent discs }(\mathrm{C} 4-5, \\
\text { C7-T1) myelopathy }\end{array}$ & $\mathrm{C} 5,6,7$ & 13.0 & 4.3 \\
\hline 3 & 54 & $\mathrm{~F}$ & Disc herniation & ${ }^{\mathrm{a}} \mathrm{AF}(\mathrm{C} 5-6)$ & $\begin{array}{l}\text { Disorder of adjacent discs }(\mathrm{C} 4-5, \mathrm{C} 6-7) \\
\text { radiculo/myelopathy }\end{array}$ & $\mathrm{C} 4,5,6$ & 5.0 & 2.2 \\
\hline 4 & 35 & M & Disc herniation & ${ }^{\mathrm{a}} \mathrm{AF}(\mathrm{C} 5-6)$ & $\begin{array}{l}\text { Disorder of adjacent discs }(C 3-4,4-5 \text {, } \\
6-7) \text { myelopathy }\end{array}$ & $\mathrm{C} 4,5,6$ & 9.7 & 1.9 \\
\hline 5 & 52 & M & $\begin{array}{l}\text { Spondylotic } \\
\text { myelopathy, disc } \\
\text { herniation }\end{array}$ & Laminoplasty (C3-7) & $\begin{array}{l}\text { Intraforaminal spur }(\mathrm{C} 4-5, \mathrm{C} 5-6) \text { slip } \\
(\mathrm{C} 3-4,4-5,5-6) \text {, radiculo/myelopathy }\end{array}$ & $\mathrm{C} 4,5$ & 2.1 & 3.1 \\
\hline 6 & 52 & M & $\begin{array}{l}\text { Spondylotic } \\
\text { myelopathy }\end{array}$ & Laminoplasty (C5-7) & $\begin{array}{l}\text { Spondylotic change, disc herniation } \\
\text { (C3-4), slip (C3-4, 6-7), radiculo/ } \\
\text { myelopathy }\end{array}$ & $\mathrm{C} 4,5,6$ & 4.5 & 2.8 \\
\hline 7 & 56 & M & OPLL & $\begin{array}{l}\text { Laminoplasty (C3-7) } \\
\text { laminectomy }(\mathrm{C} 1-2)\end{array}$ & $\begin{array}{l}\text { Insufficient recovery after first } \text { surgery } \\
\text { myelopathy }\end{array}$ & $\mathrm{C} 3,4$ & 2.2 & 1.5 \\
\hline ave. $\pm \mathrm{SD}$ & & & & & & & $5.5 \pm 4.3$ & $3.1 \pm 1.5$ \\
\hline
\end{tabular}

${ }^{\mathrm{a}} \mathrm{AF}=$ anterior fusion

${ }^{\mathrm{b}} \mathrm{PW}=$ posterior wiring 

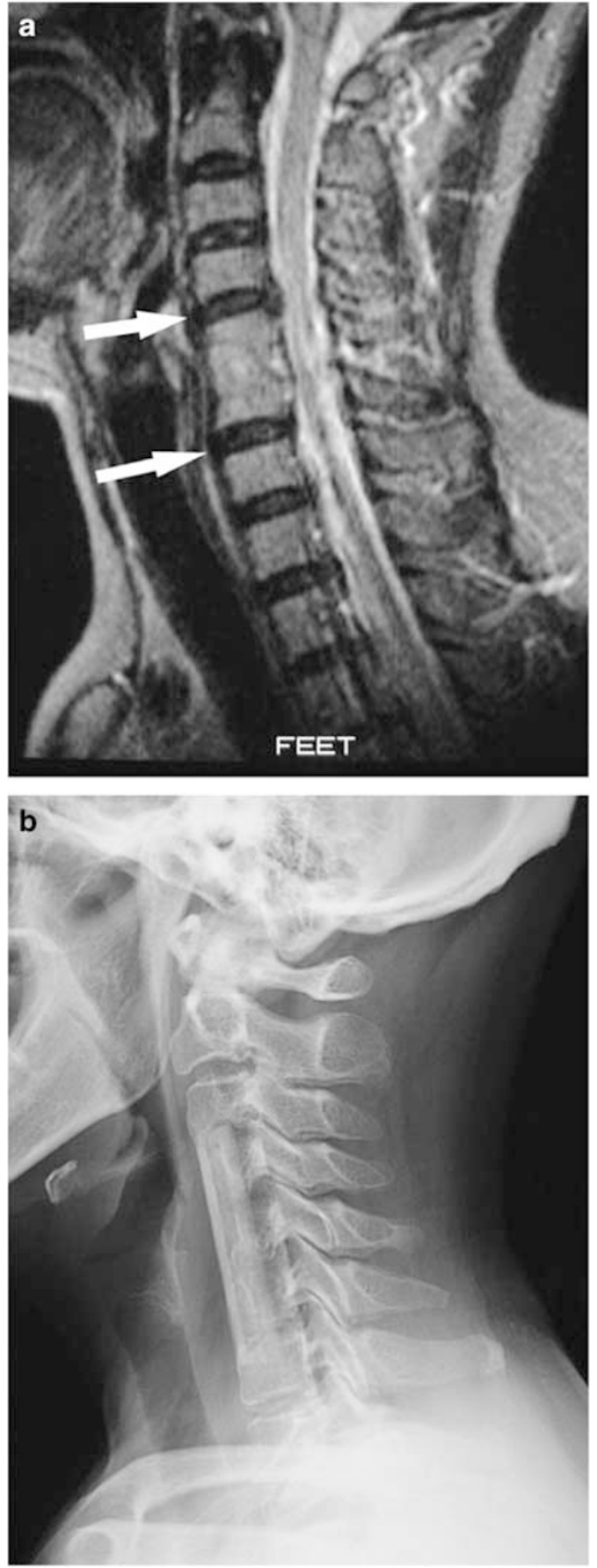

Figure 1 (a, b) Representative findings of patient 3. Pain recurred in the left upper extremity of this 54-year-old woman after C5-6 anterior discectomy and fusion. (a) Sagittal MR image demonstrating disc protrusions at the adjacent discs (C4-5, C6-7) (white arrows). (b) Lateral radiograph of the cervical spine 3 months after the corpectomy of $\mathrm{C} 4,5$, and 6 and anterior fusion from $\mathrm{C} 3$ to $\mathrm{C} 7$

worsened neurological status (patients 5-7) (Figures 2, $3 a$ and $b$ ). There were a variety of reasons for the postlaminoplasty disorders (Table 1). All patients had cervical myelopathy or radiculomyelopathy due to spinal cord compression.
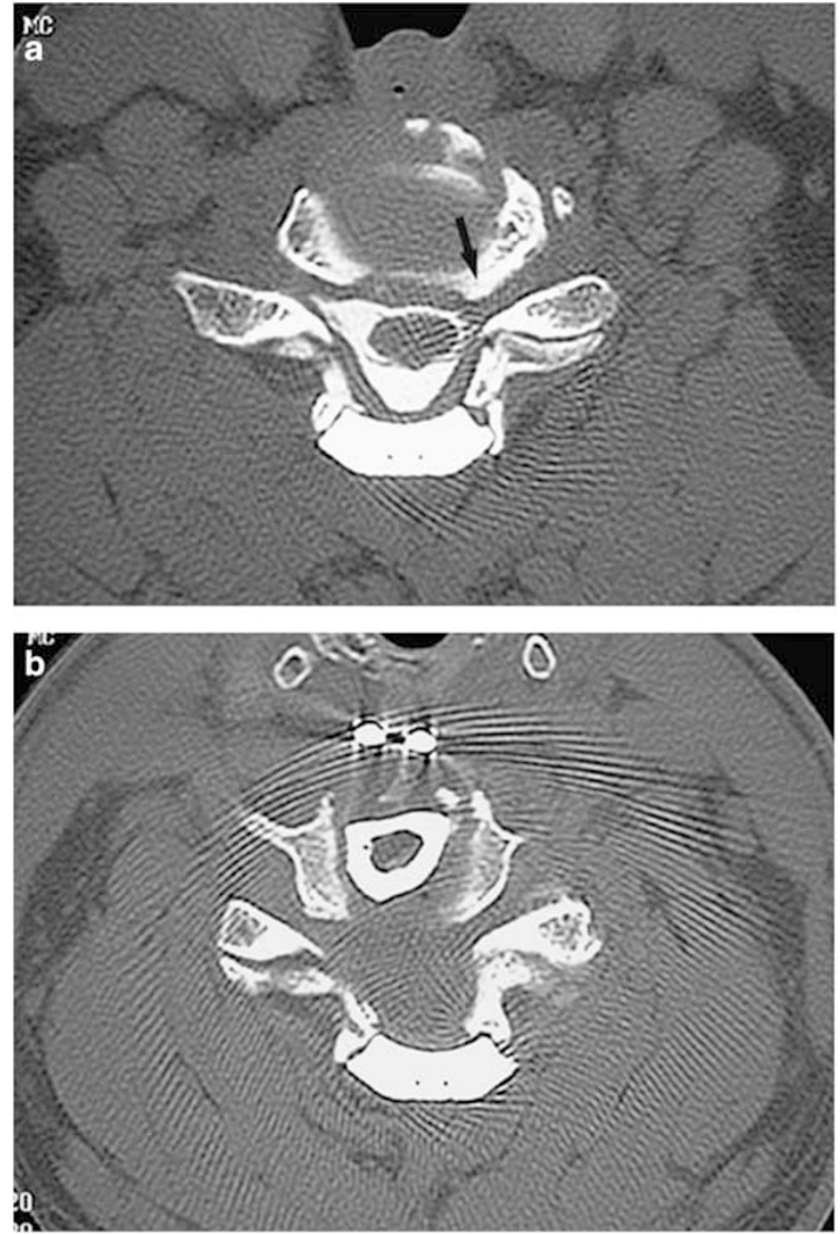

Figure 2 (a, b) Representative findings of patient 5. Pain and paresthesia remained in the left arm of a 52-year-old man who had undergone laminoplasty from C3 to C7 for cervical spondylotic myelopathy. (a) CT-myelogram demonstrated disc bulging and spur formation in the left neural foramen (black arrow) at the C5-6 level. (b) CT scan after two-level corpectomy shows successful anterior decompression

Two- or three-level ACF using autogenous fibular strut graft was performed in all the patients as revision surgery. The indications of this procedure was strictly limited to multilevel anterior lesions or evidence of multilevel intervertebral instabilities of the cervical spine, as demonstrated by physical examinations, dynamic X-rays, MRI, and myelo-CT studies. The mean interval between the first and revision operations was 5.5 years. The patients were followed up after the revision operation for 3.1 years on average.

\section{Surgical procedures}

A subtotal anterior corpectomy, with microscopic removal of the discs and all vertebral body but the lateral walls of the vertebra, was performed in all patients. The posterior longitudinal ligament was cut open in the median line. Then, autogenous fibula strut 

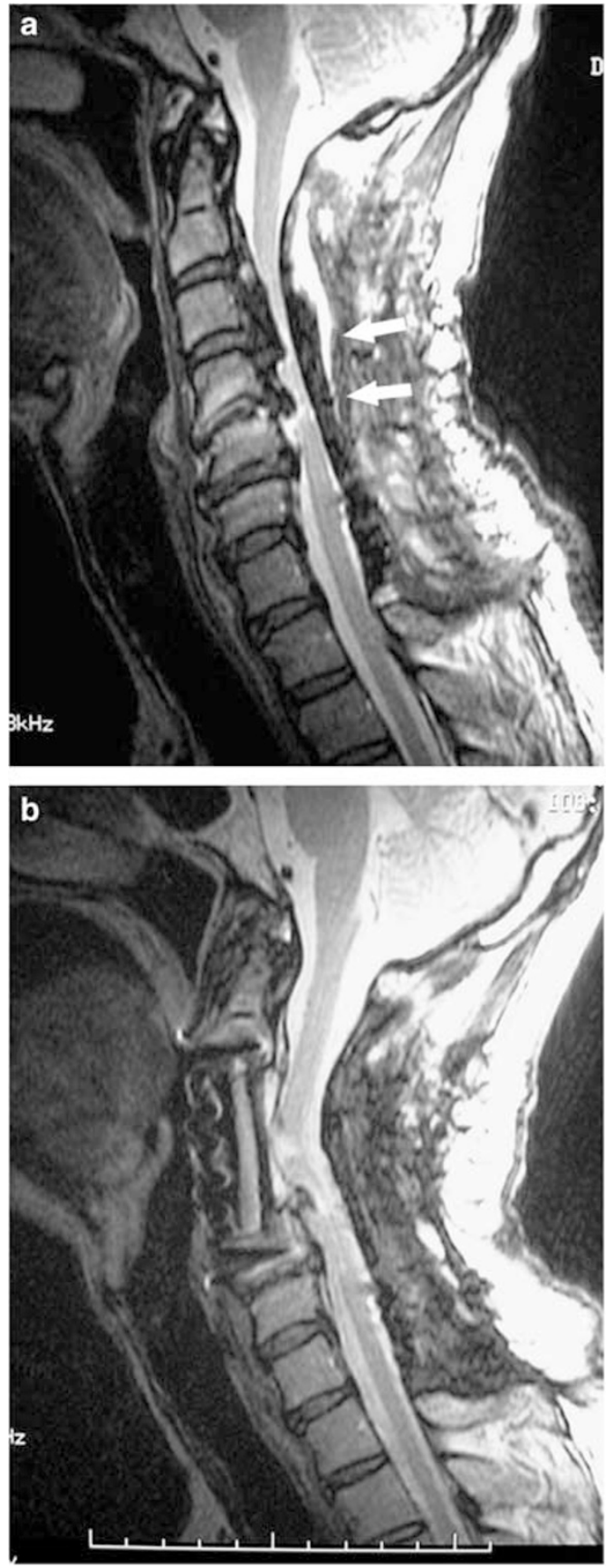

Figure 3 (a, b) Representative findings of patient 7. A 56year-old man had undergone C3-7 laminoplasty for OPLL. However, the neurological recovery was insufficient. (a) Sagittal MR image demonstrating C2-5 OPLL. After the laminoplasty, decompression for the spinal cord was insufficient (white arrows). (b) MR image after the corpectomy of C3 and 4 , and anterior fusion from $\mathrm{C} 2$ to $\mathrm{C} 5$. Ossified masses were removed and spinal cord shifted anteriorly

graft was swedged into end plate. Four patients (patients 2, 3, 4 and 6) had three-level ACF employing fibula strut autograft, while three (patients 1, 5 and 7) had two-level ACF. An anterior cervical plate (PEAK anterior cervical plate, Depuy-AcroMed, MA, USA) was employed in two patients (patients 5 and 7) who were immobilized with a hard collar until osseous fusion was confirmed. The five patients were immobilized for 3 months with halo vests, after which they worn hard collars until osseous fusion was confirmed.

\section{Evaluation of clinical outcomes \\ Radiographic evaluations}

Osseous fusion: The state of the osseous fusion was evaluated from plain X-ray films and CT. Trabecular continuity between adjacent vertebra and the fibular strut graft and, on lateral X-ray films, stability during flexion and extension of the cervical spine were evaluated. The time taken to achieve osseous fusion after the second surgery was also noted.

\section{Symptoms}

Neurological status: The neurological status was evaluated according to the Japanese Orthopedic Association (JOA) scoring system ${ }^{19}$ (Table 2), in which the maximum score is 17 . Patients were evaluated just before the first surgery, 6 months after the first surgery, just before the second surgery, and at the final follow-up.

Other symptoms: The presence of radicular pain and axial pain was evaluated. The axial pain included posterior neck pain, neck stiffness, and shoulder stiffness. ${ }^{20,21}$ We paid particular attention to these pains because the JOA scoring system does not evaluate the pain (Table 2). The severity of pain was graded according to the classification by Robinson et al, ${ }^{1}$ with modification. ${ }^{14}$ The pain was classified as mild if there was no limitation of activities, moderate if there was minimal limitation of activities with occasional use of anti-inflammatory medications, and severe if there was apparent limitation of activities with frequent use of anti-inflammatory medications for the relief of pain. ${ }^{14}$

Complications Intraoperative and postoperative complications were evaluated.

\section{Results}

\section{Radiographic evaluations}

Osseous fusion Rigid osseous fusion was achieved in seven patients 7.3 months on average (range, 5-9 months) after the second surgery.

\section{Symptoms}

Neurological status The average JOA score was $11.1 \pm 3.3$ (average $\pm \mathrm{SD}$ ) before the first surgery, $13.0 \pm 3.46$ months after the first surgery, $10.6 \pm 4.8$ just before the second surgery and $13.6 \pm 2.9$ at the final follow-up. In six patients, the JOA score was improved by 2-4 points after the second surgery. In one patient 
(patient 1), the JOA score was unchanged after the second surgery, but radicular pain in the upper extremities, which was his preoperative chief complaint was improved significantly. The JOA score did not fall in any of the patients (Table 3).

Axial pain Just before the second surgery, three patients complained of axial pain, including neck pain and shoulder stiffness. In one patient (patient 1), the axial pain was persistent even before the first surgery. In two patients (patients 4 and 6), who had undergone posterior procedures, axial pain onset several months after the first surgery. After the second surgery, the axial pain remained unchanged in one patient and improved somewhat in two patients. There were no new occurrences of axial pain.

Radicular pain Before the second surgery, all the patients had radicular pain in the upper extremities or trunk. After the second surgery, the radicular pain disappeared in four patients and improved in three.

\section{Complications}

There were no intraoperative complications. Postoperatively, we observed transient pain at the fibular donor site in two patients (patient 2 and 4). These complaints had continued for 2-3 months, but they disappeared in both patients after 6 months. Gait problems due to donor site pain were not observed.

\section{Discussion}

In this study, the JOA scores and the levels of radicular pain, which had worsened just before the second surgery, were improved significantly without neurological complications, after the multilevel ACF procedures. Rigid osseous fusion was successfully obtained in five patients without plates and in two patients with anterior plates. These results suggested that two- or three-level ACF using a strut graft was effective solution for these symptoms following failed cervical surgery.

After having undergone anterior discectomy and fusion, four patients in the present series (patients 1-4) had adjacent disc disorders, a common long-term complication. ${ }^{7,8,22}$ We performed multilevel ACF with strut graft on them, because their adjacent disc disorder involved more than two disc levels. Several surgeons have reported that strut grafting provides structural stability and multilevel arthrodesis has a high union rate. $^{22,23}$ Bohlman et $a l^{2}$ performed discectomy and interbody grafting on patients with adjacent disc disorders, but the success rate of fusion was less with multilevel procedures than with single level procedures. For the same pathological condition, Hilibrand et $a l^{2}$ demonstrated that strut grafting resulted in a higher rate $(100 \%)$ of arthrodesis than did multilevel interbody grafting $(63 \%)$. In the present study, by using fibular strut grafting, rigid osseous fusion was successfully 


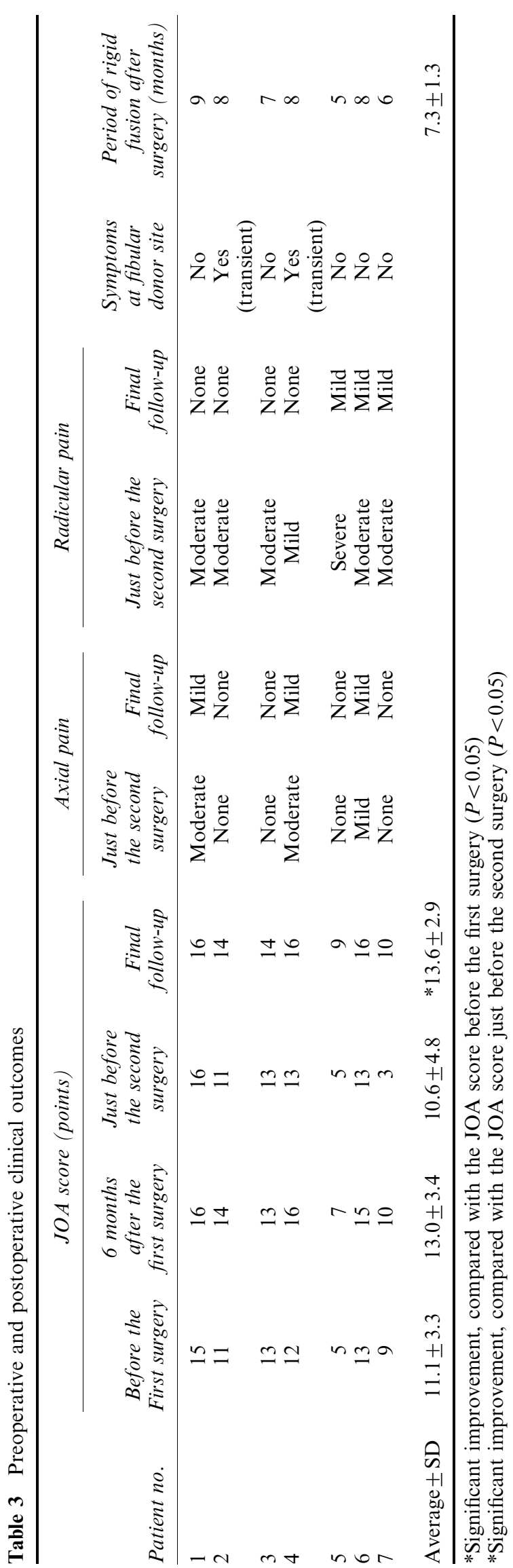

obtained in all four patients with adjacent disc disorders. In addition, autogenous grafting may be responsible for the $100 \%$ fusion rate observed in our patients. ${ }^{24}$ In two patients in this series (patients 3 and 4) normal cervical lordosis was not maintained. Therefore posterior decompressive surgeries such as laminoplasty should not be reserved for these patients without well-preserved cervical lordotic curvature. ${ }^{25}$

Three patients (patient 5-7) had postlaminoplasty disorders including secondary slip, spur formation, disc herniation, and insufficient decompression. These late-onset disorders following laminoplasty have been discussed only a little., ${ }^{6,10,11}$ In a 5-year follow of 33 patients who underwent expansive laminoplasty, Satomi et $a l^{6}$ observed the recurrence of spinal canal stenosis and neurological deterioration in six $(18 \%)$ of them. In the present series, there was a variety of reasons for the postlaminoplasty disorders. In patient 5 , radicular pain did not improve satisfactorily after the laminoplasty because of nerve root impingement at the neural foramens (Figure 2a). Baba et $a l^{15}$ showed that decompression of intraforaminal lesions by laminoplasty is tends to be unsatisfactory. In patient 6, worsening of spondylotic change and disc bulging caused spinal canal stenosis at C3-4 which had not been decompressed during the laminoplasty. In a literature search, we found only two reports of adjacent disc degeneration occurring after laminoplasty. ${ }^{11,26}$ Wang et $a l^{11}$ suggested that it occurs because of stiffening of the operated segments. In addition, in patients 5 and 6 , who had spondylotic myelopathy, we observed worsening of degenerative slip (patient 5: C3-4, C4-5, C5-6, patient 6: C3-4, C6-7). Kimura et $a l^{10}$ reported that degenerative slips were worsened in four $(14 \%)$ of 29 patients who underwent laminoplasty for spondylotic myelopathy during 7.1 years of followup. In these conditions, decompression of anterior elements and intervertebral stabilization were both necessary. In patient 7 , who had undergone laminoplasty for OPLL, neurological recovery after the first surgery was insufficient. The insufficiency of the decompression was clear from the insufficient posterior shifting of the spinal cord and was probably caused by massive anterior impingement by OPLL and malalignment of the cervical spine (Figure $3 \mathrm{a}$ and $\mathrm{b}$ ). Sodeyama et $a l^{27}$ found that posterior shifts of the spinal cord of more than $3 \mathrm{~mm}$, which is closely implicated in neurological recovery after laminoplasty, could not be expected when the cervical spine is malaligned.

Axial pain is reported to occur frequently after posterior cervical surgery such as laminoplasty. ${ }^{20,28}$ This is why we gave it particular attention in this study, despite it not being included in the JOA scoring system. In the present study, axial pain was remained in two patients after posterior surgery and in one patient after anterior surgery. The ACF revision surgery did not resolve this symptom completely in these patients and presumably, the axial pain may be a symptom from surgical damage or disuse atrophy of the nuchal muscles and ischemia of the shoulder muscles. ${ }^{14,21}$ 
In contrast, several complications have occurred after ACF with strut grafting, for example, graft extrusion, migration, and pseudoarthrosis. ${ }^{29,30}$ Some surgeons have recently performed simultaneous posterior fusion, which is useful for avoiding graft extrusion. ${ }^{31,32}$ Although we observed no graft extrusion in our patients, when there is severe malalignment of the cervical spine, such as postlaminectomy kyphosis, posterior fusion is necessary. ${ }^{29}$

To summarize, the ACF procedure, as a revision surgery, provided satisfactory results in all seven patients who had unfavorable results after previous cervical anterior fusion or laminoplasty. However, this procedure must be indicated after careful consideration of the patients' pathological condition. A long-term follow-up is necessary to demonstrate the efficacy of this procedure for cervical revision surgery.

\section{Conclusion}

Multilevel ACF using a fibular strut graft performed as revision surgeries in seven patients following failed cervical surgery was successful, at least according to a short- to mid-term follow-up. This report suggests that multilevel ACF can be performed effectively as revision surgeries in patients with adjacent disc disorders occurring after anterior fusion and with a variety of disorders occurring after laminoplasty.

\section{References}

1 Robinson RA, Walker AE, Ferlick DC, Wiecking DK. The result of anterior interbody fusion of the cervical spine. J Bone Joint Surg Am 1962; 44: 1569-1587.

2 Bohlman HH, Emery SE, Goodfellow DB, Jones PK. Robinson anterior cervical discectomy and arthrodesis for cervical radiculopathy. Long-term follow-up of one hundred and twenty-two patients. J Bone Joint Surg Am 1993; 75: $1298-1507$.

3 Riley Jr LH, Robinson RA, Johnson KA, Walker AE. The result of anterior interbody fusion of the cervical spine. Review of 93 consecutive cases. J Neurosurg 1969; 30: 127-133.

4 Hirabayashi K, Miyakawa J, Satomi K, Maruyama T, Wakano K. Operative result and potoperative progression of ossification among patients with ossification of cervical posterior longitudinal ligament. Spine 1981; 6: 354-364.

5 Itoh T, Tsuji H. Technical improvements and results of laminoplasty for compressive myelopathy in the cervical spine. Spine 1985; 10: 729-736.

6 Satomi K, Nishu Y, Kohno T, Hirabayashi K. Long-term follow-up studies of open-door expansive laminoplasty for cervical stenotic myelopathy. Spine 1994; 19: 507-510.

7 Hilibrand AS, Carlson GD, Palumbo MA, Jones PK, Bohlman HH. Radiculopathy and myelopathy at segments adjacent to the site of a previous anterior cervical arthrodesis. J Bone Joint Surg Am 1999; 81: 519-528.

8 Katsuura A, Hukuda S, Saruhashi Y, Mori K. Kyphotic malalignment after anterior cervical fusion is one of the factors promoting the degenerative process in adjacent intervertebral levels. Eur Spine J 2001; 10: 320-324.
9 Tribus CB, Corteen DP, Zdeblick TA. The efficacy of anterior cervical plating in the management of symptomatic pseudoarthrosis of the cervical spine. Spine 1999; 24: 860-864.

10 Kimura I, Shingu H, Nasu Y. Long-term follow-up of cervical spondylotic myelopathy treated by canalexpansive laminoplasty. J Bone Joint Surg Br 1995; 77: 956-961.

11 Wang MY, Green BA, Vitarbo E, Levi AD. Adjacent segment disease: an uncommon complication after cervical expansile laminoplasty: case report. Neurosurgery 2003; 53: 770-772; discussion 772-773.

12 Albert TJ, Vacarro A. Postlaminectomy kyphosis. Spine 1998; 23: 2738-2745.

13 Siambanes D, Miz GS. Treatment of symptomatic anterior cervical nonunion using the Rogers Interspinous wiring techniques. Am J Orthop 1998; 27: 792-796.

14 Wada E, Suzuki S, Kanazawa A, Matsuoka T, Miyamoto S, Yonenobu K. Subtotal corpectomy versus laminoplasty for multilevel cervical spondylotic myelopathy: a long-term follow-up study over 10 years. Spine 2001; 26: 1443-1448.

15 Baba I, Chen Q, Uchida K, Imura S, Morikawa S, Tomita K. Laminoplasty with foraminotomy for coexisting cervical myelopathy and unilateral radiculopathy. A preliminary report. Spine 1996; 21: 196-202.

16 Abumi K, Kaneda K, Shono Y, Fujiya M. One-stage posterior decompression and reconstruction of the cervical spine by using pedicle screw fixation systems. J Neurosurg Spine 1999; 90: 19-26.

17 Kim CW, Abrams R, Lee G, Hoyt D, Garfin SR. Use of vascularized fibular grafts as a salvage procedure for previously failed spinal arthrodesis. Spine 2001; 26: 2171-2175.

18 Zdeblick TA, Bohlman HH. Cervical kyphosis and treatment by anterior corpectomy and strut grafting. J Bone Joint Surg Am 1989; 71: 170-182.

19 Japanese Orthopedic Association. Scoring system for cervical myelopathy. J Jpn Orthop Asso 1994; 68: 490-503, (in Japanese).

20 Hosono N, Yonenobu K, Ono K. Neck pain and shoulder pain after laminoplasty: A noticeable complication. Spine 1996; 21: 1969-1973.

21 Yoshida $\mathrm{M}$ et al. Does reconstruction of posterior ligamentous complex with extensor muscle decrease axial symptoms after cervical laminoplasty? Spine 2002; 27: 1414-1418.

22 Hilibrand AS, Yoo JU, Carlson GD, Bohlman HH. The success of anterior cervical arthrodesis adjacent to a previous fusion. Spine 1997; 22: 1574-1579.

23 Nirala AP, Husain M, Vatsal DK. A retrospective study of multiple interbody grafting and long segment strut grafting following multilevel anterior cervical decompression. $\mathrm{Br} \mathrm{J}$ Neurosurg 2004; 18: 227-232.

24 Malloy KM, Hilibrand AS. Autograft versus allograft in degenerative cervical disease. Clin Orthop Relat Res 2002; 394: $27-38$.

25 Sani S, Ratliff JK, Cooper PR. A clonical review of cervical laminoplasty. Neurosurg $Q$ 2004; 14: 5-16.

26 Takagi H, Kawaguchi Y, Kanamori M, Abe Y, Kimura T. Case reports: T1-2 disc herniation following an en bloc cervical laminoplasty. J Orthop Sci 2002; 7: 496-497.

27 Sodeyama T, Goto S, Mochizuki M, Takahashi J, Moriya H. Effect of decompression enlargement laminoplasty for posterior shifting of the spinal cord. Spine 1999; 24: 1527-1531; discussion 1531-1532. 
28 Ratliff JK, Cooper PR. Cervical laminoplasty: a critical review. J Neurosurg 2003; 98: 230-238.

29 Riew KD, Hilibrand AS, Palumbo MA, Bohlman HH. Anterior cervical corpectomy in patients previously managed with a laminectomy: short-term complications. $J$ Bone and Joint Surg Am 1999; 81: 950-957.

30 Wang JC, Hart RA, Emery SE, Bohlman HH. Graft migration or displacement after multilevel cervical corpectomy and strut grafting. Spine 2003; 28: 1016-1021; discussion 1021-1022.
31 Epstein NE. Posterior cervical fusion failure in three morbidly obese patients following circumferential surgery. Surg Neurol 2003; 60: 205-210; discussion 210.

32 Schultz Jr KD, McLaughlin MR, Haid Jr RW, Comey CH, Rodts $\mathrm{Jr}$ GE, Alexander J. Single-stage anteriorposterior decompression and stabilization for complex cervical spine disorders. J Neurosurg Spine 2000; 93: 214-221.

33 Saunders RL, Pikus HJ, Ball P. Four-level cervical corpectomy. Spine 1998; 23: 2455-2461. 